\title{
Risk based management of chemicals and products in a circular economy at a global scale (risk cycle), extended producer responsibility and EU legislation
}

Uwe Lahl $^{1^{*}}$ and Barbara Zeschmar-Lahl ${ }^{2}$

\begin{abstract}
Background: Global waste recycling streams are accompanied by pollutant emission and concentration of hazardous substances within material cycles. For the latter, the term "risk cycle" is introduced. E.g. the illegal or semi-legal export of hazardous wastes like electronic scrap in developing countries for recycling is associated with risks for man and the environment, based on toxic and/or persistent chemical components of the discarded products.

Results: The problem of cycling of pollutants within global waste recycling streams (risk cycle) can be solved in principle with the aid of REACH regulations. According to the demands of the REACH guidance documents, risk cycle associated emissions would have to be identified during the development of exposure scenarios and to be reduced by risk management measures. This would also apply to chemicals in electronic scrap as they pose health risks to workers at recycling sites with poor working conditions e.g. in Africa and Asia - regardless if exported illegally. Therefore it is necessary to check whether the substance dossiers of these chemicals, that have or had to be submitted under REACH, have considered such exposure scenarios.

Conclusions: Following the extended producer responsibility, there is a need for action. Within the context of European legislation, risk cycle of pollutants can be particularly addressed in the framework of the European chemicals legislation REACH. The legal options are given in principle. However, it is unclear whether the waste life cycle stage (risk cycle) has been and is included sufficiently within substance registration and regulatory review of the registration dossier. Integrating the effects of recycling in developing countries into the REACH regulation is undoubtedly a major challenge. But without doubt avoiding the cycling of pollutants within global waste recycling streams (risk cycle) is a major challenge, too, and in addition one of the core tasks of extended producer responsibility.
\end{abstract}

Keywords: Risk cycle, REACH, Exposure scenarios, Registration, Extended producer responsibility, Electronic scrap recycling

\footnotetext{
* Correspondence: u.lahl@iwar.tu-darmstadt.de

${ }^{1}$ Technische Universität Darmstadt, Institut IWAR, Petersenstr. 13, Darmstadt

D-64287, Germany

Full list of author information is available at the end of the article
} 


\section{Background}

When analyzing the results of the RISKCYCLE project [1] on the main points, it is then clear that selected hazardous pollutants (chemical additives) that are contained in consumer and industrial products, are circulated ultimately globally because of the containing products' entry into the waste/recycling path. These global pollutant cycles are likely to pose risks to humans and the environment, but for a final evaluation many basic data are lacking.

The topic of this article is: How can the outcome of the project RISKCYCLE influence European legislation? In fact, there are different routes for implementing the idea of risk cycle in regulations like e.g. the Ecodesign Directive, the European waste legislation, and REACH.

First, the Ecodesign Directive is another possibility to implement more precaution against the cycling of pollutants within waste streams. So far, the idea of hazards and risks in the design of products was not well documented under this roof. Actually, there is a discussion on the European level to widen the scope of the Ecodesign Directive.

Second, what about using European waste legislation? The Restriction of Hazardous Substances Directive (RoHS) was very successful. The RoHS Directive is closely linked with the Waste Electrical and Electronic Equipment Directive (WEEE) which sets collection, recycling and recovery targets for electrical goods and is part of a legislative initiative to solve the problem of toxic e-waste. Is there a perspective to add further such directives one by one, to tackle the cycling of pollutants within waste streams?

And third, REACH - the European chemicals legislation - has interrelation to the waste sector and therefore to the problem of risk cycle. Furthermore there is an actual discussion about amending REACH. What amendments could be meaningful to avoid the cycling of pollutants within waste streams?

In this contribution the authors discuss the suitability of these three routes [2].

\section{Avoiding the cycling of pollutants within global waste recycling streams Possible routes for avoiding the cycling of pollutants}

The need for avoiding the cycling of pollutants within waste streams is obvious. There are three possible routes for tackling this problem.

\section{Route 1: Ecodesign Directive}

The Ecodesign Directive is the regulation that sets the standards for products (products, goods) at EU level. Thus, for the risk cycle issue, it could establish regulations in principle for the pre-consume phase, so that only those chemical additives may be added that do not cause problems in a sustainable closed substance cycle.

Originally only products having energy consumption were considered as part of the EU Ecodesign Directive. The scope of the Directive was extended in 2009 to the range of products that are related to energy consumption (energy related, such as windows, insulation).

The EU Commission may establish minimum standards to improve efficiency of energy-related products (ErP). Although energy is in the focus of the Directive, other kinds of resource consumption are considered, too. This is illustrated by the evaluation methodology MEEuP (Methodology for the Ecodesign of Energy-using Products), which is basic for the implementation of the Ecodesign Directive [3]. Under the heading MEErP (Methodology for the Ecodesign of Energy-related Products) this method is actually passing an evaluation and completion process due to the expansion of the scope of the Directive [4]. The Eco-Report 2011 is an Excel-based pre-computation method to assess resource efficiency of products [5]. From this it is clear which indicators are to be applied in future implementation of the Ecodesign Directive.

The European Commission has adopted a formal working plan for the implementation of the Directive. The working plan 2009 to 2011 set out an indicative list of products and product groups, which were processed successively and in the end, also regulated (airconditioning and ventilation systems; electric and fossilfuelled heating equipment; food-preparing equipment; industrial and laboratory furnaces and ovens; machine tools; network, data processing and data storing equipment; refrigerating and freezing equipment; sound and imaging equipment; transformers; water-using equipment) [6]. The regulation of each type of product group had been preceded by an expert study (preparatory study), which had been afterwards scrutinized intensively in a stakeholder process.

The Commission's new working plan 2012 to 2014 has been published in December 2012 [7]. It contains an indicative list of twelve broad product groups to be considered between 2012 and 2014 for the adoption of implementing measures. As there is the possibility that overlaps exist with a number of ongoing preparatory studies and regulations due for review, the list of product groups has been split into a priority list (window products; steam boilers < $50 \mathrm{MW}$; power cables; enterprises' servers, data storage and ancillary equipment; smart appliances/meters; wine storage appliances (c.f. Ecodesign regulation 643/ 2009) and water-related products) and a conditional list (positive displacement pumps; fractional horsepower motors < 200 MW; heating controls; lighting controls/ systems; thermal insulation products for buildings).

How can the Ecodesign Directive be further developed to handle the topic of cycling of pollutants within waste 
streams? So far, pollution issues are involved in the context of product evaluation and the derivation of product standards, but rather in the sense of LCA to capture the environmental conditions/emissions merely connected to energy. But the topic of mercury in compact fluorescent lamps (CFL) has made it clear that pollution issues can be quite important in the context of this Directive. The relevant limits for energy saving lamps were first set by a waste-related regulation, namely in the Annex of the WEEE Directive [8].

Actually there is a discussion within the Commission on the evaluation of the Ecodesign Directive. One of the positions taken is to expand the scope of the directive a second time, to broaden its field of application. There are some voices proposing to include the pollution issue in the context of setting product standards.

Currently, the Ecodesign Directive can include selected pollutants in life cycle assessment considerations, see [5]. The recommended methodology does however not cover the topic of the cycling of pollutants within waste streams:

\section{"In the MEErP 2011 methodology the analysts are required to give the materials flows to re-use (including closed loop recycling whereby a part of the original plastics can indeed be re-used), materials recycling, energy recovery (a.k.a. 'thermal recycling') and disposal. The credits for recycling fractions are based on down-cycling/open loop recycling [4, p. 98]. ... The credit relates to the recyled mass and depends on the main virgin material that will be displaced by the recycled mass, the remaining value at final disposal (e.g. heat recovery) and/or avoidance of operations for disposal of hazardous substances (pyrolysis)" [4, p. 124].}

At present it is unclear whether the scope of the Ecodesign Directive will be extended a second time and whether the problem of pollutants in products will be involved. Since the focus of the policy will remain clearly on the energy aspect it is not expected that even with expansion of the scope, the Ecodesign Directive can make a relevant contribution to solving the problem of cycling of pollutants within waste streams.

\section{Route 2: Waste legislation}

In the past, product-related standards in the European waste law were rare. This changed with the triumphal success of everyday electronic gadgets and the associated increase in e-scrap. The EC Directive 2002/96/EC - better known as WEEE Directive (an acronym for Waste Electrical and Electronic Equipment) - aimed to combat the increasing amount of e-waste from electrical and electronic devices no longer used [9]. Goal is the avoidance, reduction, and environmentally friendly disposal of increasing amounts of electronic waste through extended producer responsibility. This goal has been hindered by a number of pollutants that had been processed in the devices.

For solving this problem, the WEEE Directive has been complemented with an additional directive that limits the use of certain pollutants in these products. The EC Directive 2002/95/EC on the Restriction of the use of certain Hazardous Substances in electrical and electronic equipment (RoHS Directive) ([8], recast 2011 [10]) restricts the use of six harmful substances/substance families in equipment and components to $0.1 \%$ (lead, mercury, hexavalent chromium, polybrominated biphenyls (PBB) and polybrominated diphenyl ethers (PBDE)) or $0.01 \%$ (cadmium), but with several exemptions for a wide range of applications (Annex III and IV).

In particular, the RoHS Directive has been proven to be successful in Europe. Those substances are now banned from the products (below the limit values). Furthermore the international equipment manufacturers have switched their production, not limited to Europe, but made for the world market. This in turn has led to the creation of laws similar to the RoHS regulation in other regions of the world.

In the sector of electrical and electronic equipment, the RoHS Directive, as explained, has successfully fought an increase of risk cycle and has reduced many problems. This raises the question whether the RoHs Directive can offer a further contribution for solving the risk cycle problem. This would require an extension of the scope of the Directive in two aspects:

- expansion of product scope to other products in addition to electrical and electronic equipment and

- extension of the catalog of restricted substances (Annex II of Directive).

Article 6 of the RoHS Directive (recast 2011 [10]) says:

"1. With a view to achieving the objectives set out in Article 1 and taking account of the precautionary principle, a review, based on a thorough assessment, and amendment of the list of restricted substances in Annex II shall be considered by the Commission before 22 July 2014, and periodically thereafter on its own initiative or following the submission of a proposal by a Member State ...".

Thus, the door would be open for this extension. Whether it succeeds also to extend the scope of the Directive on other risk cycle-related products is doubtful. No such advances are known.

Furthermore, the instrumentation of the RoHS Directive has to be considered in this context. The Directive is 
heading towards a clearly structured business sector with very few clear substance bans (or more precisely: limits). For the regulated pollutants in turn very unique risk considerations are possible. Without an extension of the instrumentation to a more sophisticated control system, the complex (chemical) process cannot be reproduced in other sectors.

\section{Route 3: REACH - the European chemicals legislation}

$\mathrm{REACH}$ is in force for up to now six years. REACH is setting the legal frame for the chemical sector. But REACH also gave a task, which is to work off for more than 15 years: a "safety check" for all existing chemicals.

This "safety check" is in the first approach a check, the responsible manufacturer or importer has to do in his own responsibility. In a second approach, it is to some extent also a check, which is done by the competent authorities, especially the European Chemicals Agency (ECHA) and the national authorities.

For this, the manufacturer and the importer have to register the chemicals they are bringing on the European market. The registration is obligatory for all chemicals that are sold in a volume bigger than $1,000 \mathrm{~kg} / \mathrm{a}(=1$ $\mathrm{Mg} / \mathrm{a})$. With the registration the manufacturer and the importer have to provide a special registration dossier. This dossier should cover all necessary information to do the "safety check". To be precise, the structure of the dossier has to follow well defined requirements, which will not be explained in this article. More information is offered here $[11,12]$.

Meanwhile the first "tranche" for the registration is done for all chemicals with a market volume of more than 1,000 tons per annum and for chemicals, which have a high concern out of hazardous reasons (e.g. carcinogenic, mutagenic or toxic to reproduction (CMR)). By the REACH deadline of 30 November 2010 for the first tranche, 24,675 registration dossiers have been submitted for 4,300 substances including nearly 3,400 phase-in substances [13]. In the coming years the rest of the existing chemicals have to be registered. Currently the evaluation of the dossiers takes place.

The $\mathrm{REACH}$ regulation has the item that after a five years period there should be an evaluation of the regulation itself. First the commission has to give a report about the lessons learned:

"The Commission will launch a review which will consist of the legally required reviews and reports: (a) the review of ECHA (Article 75.2), (b) the review to assess whether or not to amend the scope of REACH in order to avoid overlaps with other EU legislation (Article 138.6), and (c) a general report from the experience acquired in the operation of the regulation (Article 117.4) including a review of the requirements relating to registration of low tonnage substances Article 138(3) and the information submitted by the Member States and ECHA in their respective reports on the operation of REACH (Art.117(1)(2)(3)" [14].

This evaluation is on the way. The different stakeholders have made their proposals, what should be modified or supplemented. Our proposals like improvement of transparency, installation of a positive list and a household product database (HPDB) have been published some months ago, including the topic $\mathrm{REACH}$ and risk cycle [15]. This article only covers the topic risk cycle, but more in depth.

\section{Result and discussion}

\section{$\mathrm{REACH}$ - the most promising route} REACH regulations on waste

The RISKCYCLE project deals with chemicals beyond their actual use phase, when they have entered the phase after end of service life, that means the waste phase. But is this area not considered legally outside the scope of $\mathrm{REACH}$ and more covered by waste legislation? The answer to this question is quite clear. Without doubt $\mathrm{REACH}$ covers the waste period, too. Thus, REACH is also suitable in principle to implement the findings of the RISKCYCLE project by legislation or regulation.

As Article 2(2) of REACH provides that "waste as defined in Directive 2006/12/EC is not a substance, mixture or article within the meaning of Article 3 of this Regulation" REACH requirements for substances, mixtures and articles do not apply to waste. But as soon as a material or a waste 'ceases to be waste', it becomes instead a product in the eyes of the EU's legislators and is falling under the $\mathrm{REACH}$ regulation.

\section{$\mathrm{REACH}$ regulations on recovered materials}

Waste fractions leaving the recycling process of waste as a recovered material have to fulfill the obligations of the REACH regulation, but with certain privileges. Article 2 (7d) provides under certain conditions for an exemption from registration (Title II), downstream user regulations (Title V) and evaluation (Title VI) [11]:

7. The following shall be exempted from Titles II, $V$ and VI:

(d) substances, on their own, in preparations or in articles, which have been registered in accordance with Title II and which are recovered in the Community if:

(i) the substance that results from the recovery process is the same as the substance that has been registered in accordance with Title II; and

(ii) the information required by Articles 31 [i.e. requirements for Safety Data Sheets] or 32 [i.e. the duty to communicate information down the supply 
chain for substances on their own or in preparations for which a safety data sheet is not required] relating to the substance that has been registered in accordance with Title II is available to the establishment undertaking the recovery.

This means, if the recovered material is identical to a substance already registered and if the information on hazardous properties are available e.g. from the safety data sheet, a registration is no longer mandatory.

But when does a material or a waste 'cease to be waste'? The end-of-waste status is specified in Article 6 of the revised Waste Framework Directive 2008/98/EC:

"1. Certain specified waste shall cease to be waste ... when it has undergone a recovery, including recycling, operation and complies with specific criteria to be developed in accordance with the following conditions:

(a) the substance or object is commonly used for specific purposes;

(b) a market or demand exists for such a substance or object;

(c) the substance or object fulfills the technical requirements for the specific purposes and meets the existing legislation and standards applicable to products; and

(d) the use of the substance or object will not lead to overall adverse environmental or human health impacts.

The criteria shall include limit values for pollutants where necessary and shall take into account any possible adverse environmental effects of the substance or object.

2. ... End-of-waste specific criteria should be considered, among others, at least for aggregates, paper, glass, metal, tyres and textiles."

ECHA points out that some materials currently considered as waste might in future be considered to have 'ceased to be waste' [16]. These materials will then be out of the scope of waste legislation, and - if not covered by an exemption - will potentially fall under REACH. Clarification of end-of-waste criteria is a matter for waste legislation. In accordance with the general principle of subsidiarity of the European Union law, and following the revised Waste Framework Directive, Member States may decide case by case whether certain waste has 'ceased to be waste', where end of waste criteria have not been set at Community level. Member States have already worked for use of this regulation, like e.g. the Waste Quality Protocol in England, Wales and Northern Ireland [17].

Actually the Commission is working on establishing end-of-waste criteria for a number of specific recyclable materials including metal scrap of copper, aluminium and iron, waste paper, waste glass, compost, and plastics. Based on the results of two frontrunner studies on ferrous scrap and aluminium scrap in 2010, the first End-of -Waste Regulation (333/2011/EC) has been adopted [18]. It applies to the EU since October 9, 2011. Following JRC/SUSPROC, based on a second round of technical studies on waste paper, copper and copper alloy scrap, as well as waste glass (glass cullet), regulations for end-of-waste on these materials are currently being prepared in the "comitology" procedure [i.e. assistance of the Commission in exercising its implementing powers by representatives of the Member States through committees [19]]. Further studies are performed on biodegradable waste and waste plastics, and the development of end-of-waste criteria on aggregates and waste-derived fuels is in discussion [20].

$\mathrm{REACH}$ regulations on waste life cycle stage of substances $\mathrm{REACH}$ requirements for substances, mixtures and articles do not apply to waste itself. "Nevertheless manufacturers and importers of substances, downstream users and potentially recipients of articles have a number of duties under REACH related to substances in waste. Waste-related information must be included in the registration dossier for all substances, including those for which no CSR [i.e. Chemical Safety Report] and/or SDS [i.e. Safety Data Sheet] is required (< $10 \mathrm{t} / \mathrm{a})$ or which are not classified as dangerous" [21].

With regard to risk cycle, the obligations for products containing hazardous substances are of great concern, as a risk characterization is mandatory. Following Article 14(4) of REACH, the Chemical Safety Assessment (CSA) shall include the following additional steps if the substance meets the criteria for classification as dangerous in accordance with Directive 67/548/EEC or is assessed to be a PBT (persistent, bioaccumulative and toxic) or $\mathrm{vPvB}$ (very persistent and very bioaccumulative):

(a) exposure assessment including the generation of exposure scenario(s) (or the identification of relevant use and exposure categories if appropriate) and exposure estimation;

(b) risk characterisation.

For these substances, "the waste life stage of the substance needs to be covered by suitable exposure scenarios, the corresponding exposure estimation and the related risk characterisation. The conditions ensuring control of risk in the waste life stage of the substance need to be documented in the chemical safety report (CSR) and also communicated in the supply chain by means of the extended Safety Data Sheet" [16]. 
Article 3(37) of REACH defines exposure scenarios as "the set of conditions, including operational conditions and risk management measures, that describe how the substance is manufactured or used during its life-cycle and how the manufacturer or importer controls, or recommends downstream users to control, exposures of humans and the environment [...]".

The Chemical Safety Assessment (CSA) has to cover the whole life cycle of the substance in the exposure assessment. Following Annex I paragraph 5.2.2 of REACH the waste life stage is to be assessed where relevant:

"The emission estimation shall consider the emissions during all relevant parts of the life-cycle of the substance resulting from the manufacture and each of the identified uses. The life-cycle stages resulting from the manufacture of the substance cover, where relevant, the waste stage. The life-cycle stages resulting from identified uses cover, where relevant, the service-life of articles and the waste stage. The emission estimation shall be performed under the assumption that the risk management measures and operational conditions described in the exposure scenario have been implemented."

Furthermore, following Annex I paragraph 5.1.1 of REACH, the Risk Management Measures (RMM) of an Exposure Scenario shall in particular include, where relevant, a description of "the waste management measures to reduce or avoid exposure of humans and the environment to the substance during waste disposal and/or recycling."

\section{Risk management measures of exposure scenarios}

ECHA's Guidance on information requirements and chemical safety assessment, Chapter R.18, gives detailed information about exposure scenario building and environmental release estimation for the waste life stage.

This Guidance is part of a series of guidance documents that aim to help all stakeholders with their preparation for fulfilling their obligations under the REACH regulation. The Guidance consists of two major parts: Concise guidance (Part A to G) and supporting reference guidance (Chapters R.2 to R.20), see Figure 1 from [21].

Figure 2 illustrates the workflow and location in the guidance of the relevant information for Chapter R.18 [21].

Registrants can choose which kind of approach they want to use for the quantitative exposure assessment for the waste life stage. The guidance contains examples for calculation of releases at local and at regional scale, as they are driven by the operational conditions and risk management measures relevant for the different uses. The assessment of distribution and fate of the substance in the environment mainly driven by substance properties, once the substance has been released to the environment, is only addressed in Guidance R.16 [22], as this step is independent of the life cycle stage. The guidance contains in addition workflows for the generic and the specific approach.

In the following, the approach for the releases at regional scale is described. Figure 3 provides an overview of waste generation during the life cycle of a substance and examples of related possible sources of information [21].

For calculation of the waste life stage's contribution to the release of the substance at regional scale, a standard model of a European region with about 20 million inhabitants and defined parameters (e.g. size, volume of water, soil, sediments and biota, etc....) is used; details are given in Chapter R.16: Environmental Exposure Estimation [22].

"In order to calculate the regional releases from waste treatment in the default conservative approach (Tier 1), again two cases are distinguished: $i$ ) Waste from manufacture and industrial uses and ii) waste from dispersive uses and article service life. The fraction of the registrant's total amount per use assumed to be treated in the region $\left(Q_{\text {max, regional }}\right)$ is different for the two cases: For manufacture and industrial uses the total use and related waste amount is assumed to occur in one region. For dispersive use and article service life, it is assumed that $10 \%$ of the registrant's total volume occurs in the region for use and related waste treatment" [20].

At regional scale all the releases occurring at the different life cycle stages are summed up. Figure 4 from [21] shows the input parameters and the results of the release assessment at regional scale. The outputs are the annual amounts of substance released to the different environmental compartments (regional air, regional water, regional soil).

As an alternative to these calculations, the registrant may choose to make a generic release estimate. Here, conservative default values are used for identifying waste amounts and fractions entering into the three main waste streams. "Furthermore, generic exposure scenarios can be selected containing default release factors and assumptions on implemented risk management in the processes" [21].

Figure 5 from [21] shows the workflow for a generic approach. "In order to simplify and structure the exposure assessment of the waste stage, the current assessment approach distinguishes three main waste streams, each of which is connected with the most typical waste treatment processes: municipal waste $(M W)$, recycling waste $(R W)$ and hazardous wastes (HW) (see Section R.18.2.2)" [21]. 


Concise Guidance In Depth Guidance

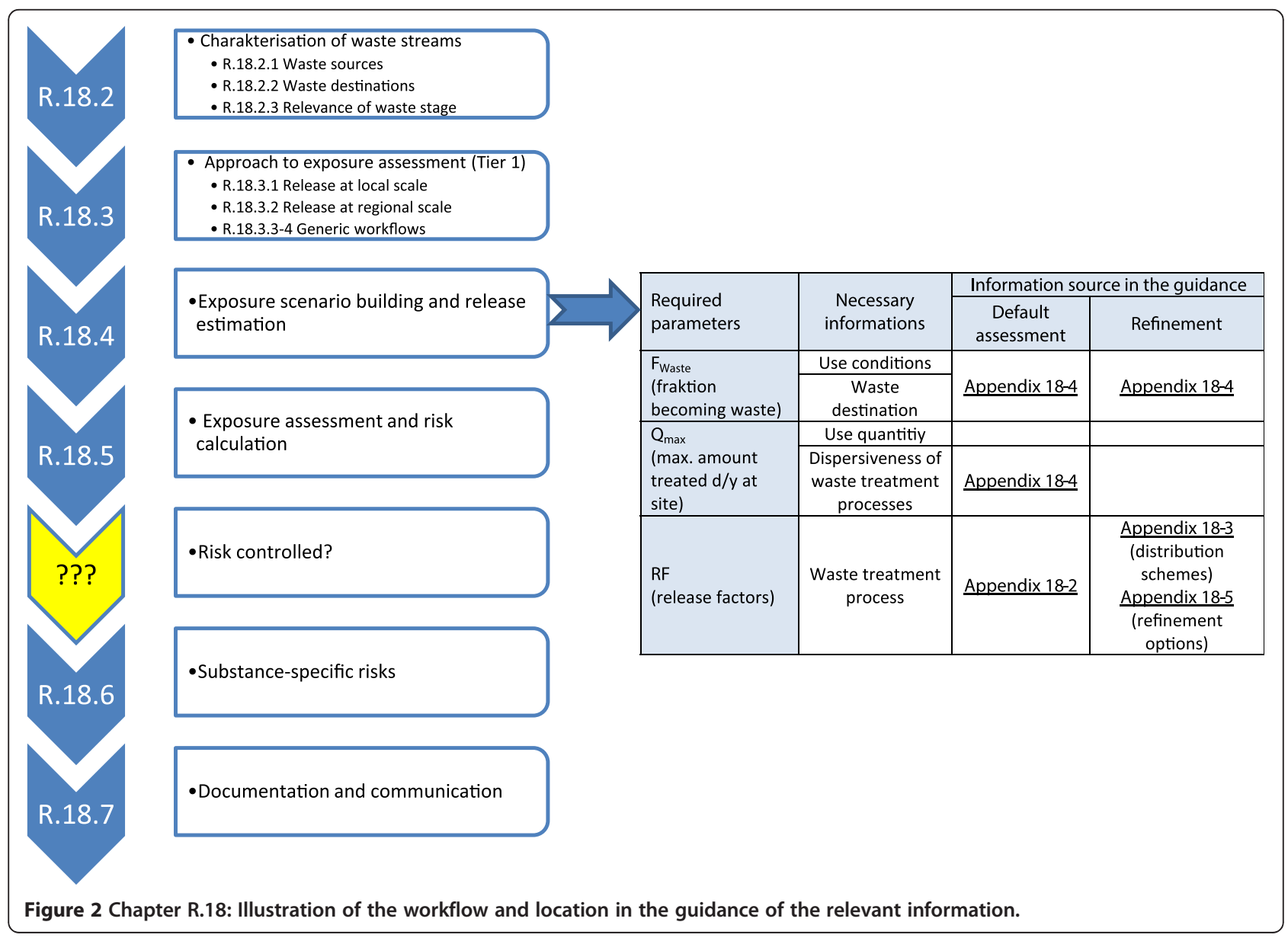


Intended vs. Unintended use

Within the risk analysis, particularly in the waste life stage, the question of whether a use is intended or not plays a significant role. Therefore it's no wonder that within the derivation of generic emission categories (environmental release categories, ERC) the question of where to draw the boundary leads to controversial discussions between industry (wants very specific stipulations) and ECHA (wants "use" to be understood more broadly) [23]. Following the position of the chemical industry, the deliberate improper use of a chemical cannot be part of an exposure calculation and related risk analysis. On the other hand some application errors when handling chemicals or downstream applications in the life cycle of a product have to be included in the exposure assessment. So this is quite a gray area that is difficult to handle.
It is clear that the waste life stage, when the substances (including substances in products) can enter the environment, has to be assessed in detail. The waste phase thus belongs to the intended use. For this assessment, however, the European state of the art is used. The emission factors are derived on the basis of European legal standards set for disposal facilities.

Although these estimates should include also so-called worst case situations, there remains a discrepancy. Especially the research activities within the RISKCYCLE project have shown that the outstanding environmental problems of the waste life stage occur outside of Europe, where the European standards are far from being reached. In addition, here emission scenarios are the rule (e.g. manually disassembling and open burning of electronic scrap) which cannot reasonably be applied the same criteria as for a risk assessment in Europe. In 


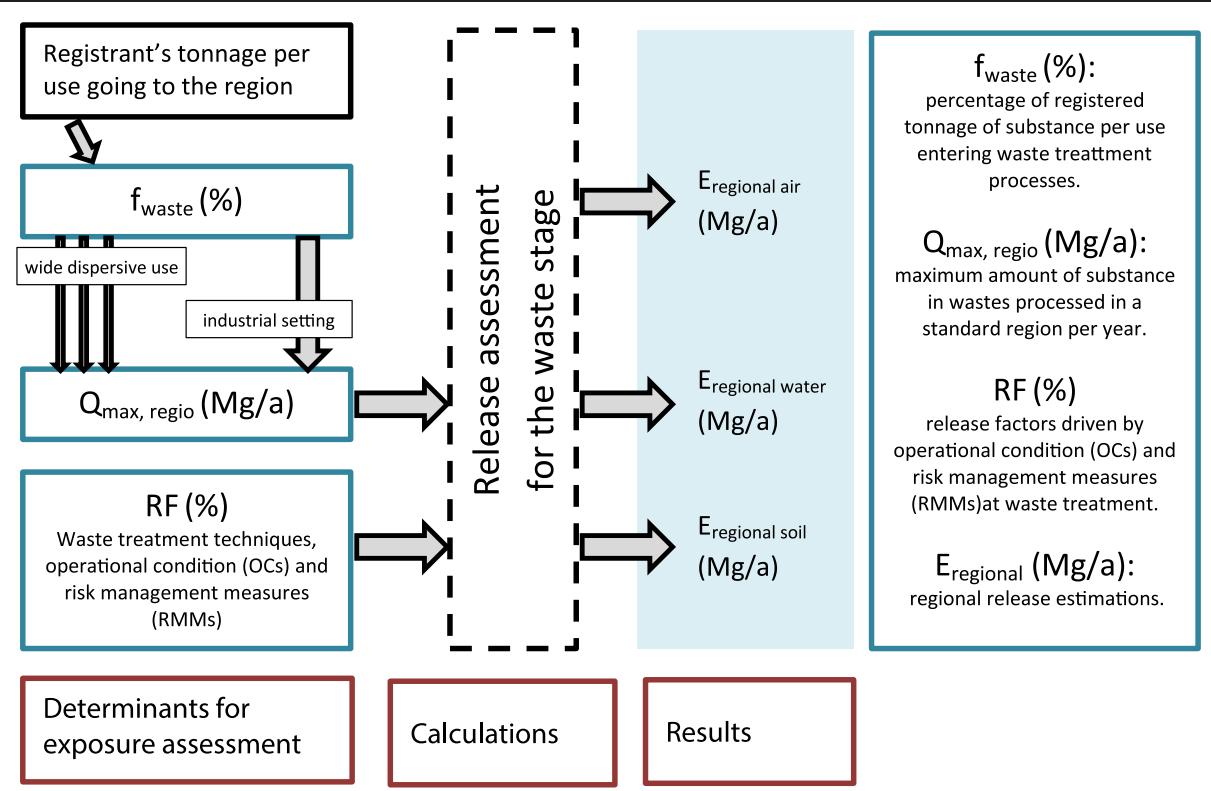

Figure 4 Determinants and results of regional release estimation for the waste life stage.

addition, according to the understanding of the exporting business actors, the transition to the waste life stage takes place only at the sites of the host developing countries. In these countries, the transition of the waste life stage into the product life stage takes regularly place for subsets of the materials (risk cycle). This in turn will not happen on the European standard and will certainly be considered as unintended use by the European registrant.

In sum, it will not be easy to integrate these so-called excesses of exports and "recycling" of substances in articles in developing countries into the $\mathrm{REACH}$ regulation. But the claim to the emission assessment is global in case of global mass flows. The regulatory question in the heart of the matter therefore is of whether the exposure scenario for registration of e.g. a brominated flame retardant has to include the known practice of electronic scrap "recycling" in e.g. Ghana or Vietnam. And this would then result in very precise exposure scenarios for local jobs. Our answer to this question is 'yes', because in these countries, this practice is "intended".

REACH and the cycling of pollutants within global waste recycling streams (risk cycle) - a short summing-up

The research project RISKCYCLE has compiled relevant information highlighting the risks of chemicals that are recycled in regional and global systems. Many of these risks are being provoked due to the fact that manufacturers of chemicals or of other items did not make efforts to pursue the item and its chemicals along its/ their way in product cycle up till the waste stage. The waste stage is not being appropriately taken into consideration in life cycle assessments.

It is approximately six years ago since the European law on chemicals REACH came into force. It was implemented to audit the risks of all chemicals on the market by their sales volume and hazardousness. The essential aim of this security check is to determine socalled "exposition scenarios", which facilitates the assessment of the occurrence of unacceptable or dangerous exposure created by the evaluated chemical. If such risks are identified, measures are to be taken to reduce the exposure by restrictions on usage or by issuing a ban.

This information is to be submitted to the authorized European Chemicals Agency (ECHA) for the purpose of substance registrations (details see above). The essential information should be recorded in the safety data sheet (SDS) of each chemical including exposition scenarios in case they are substantial. This article describes the importance of the waste life stage in the drafting of exposition scenarios. The waste phase is to be included in the calculation of exposure. As part of the implementation of $\mathrm{REACH}$, guidance documents were developed with detailed recommendations which describe how this is to be done. Important aspects of this procedure are explained above.

As a consequence of the implementation of REACH, many problems described in the RISKCYCLE project would become relevant. These described gaps in knowledge are in parts to be extracted from the registration dossiers. The information will be gained depending on the processing status of REACH registrations. Currently, 


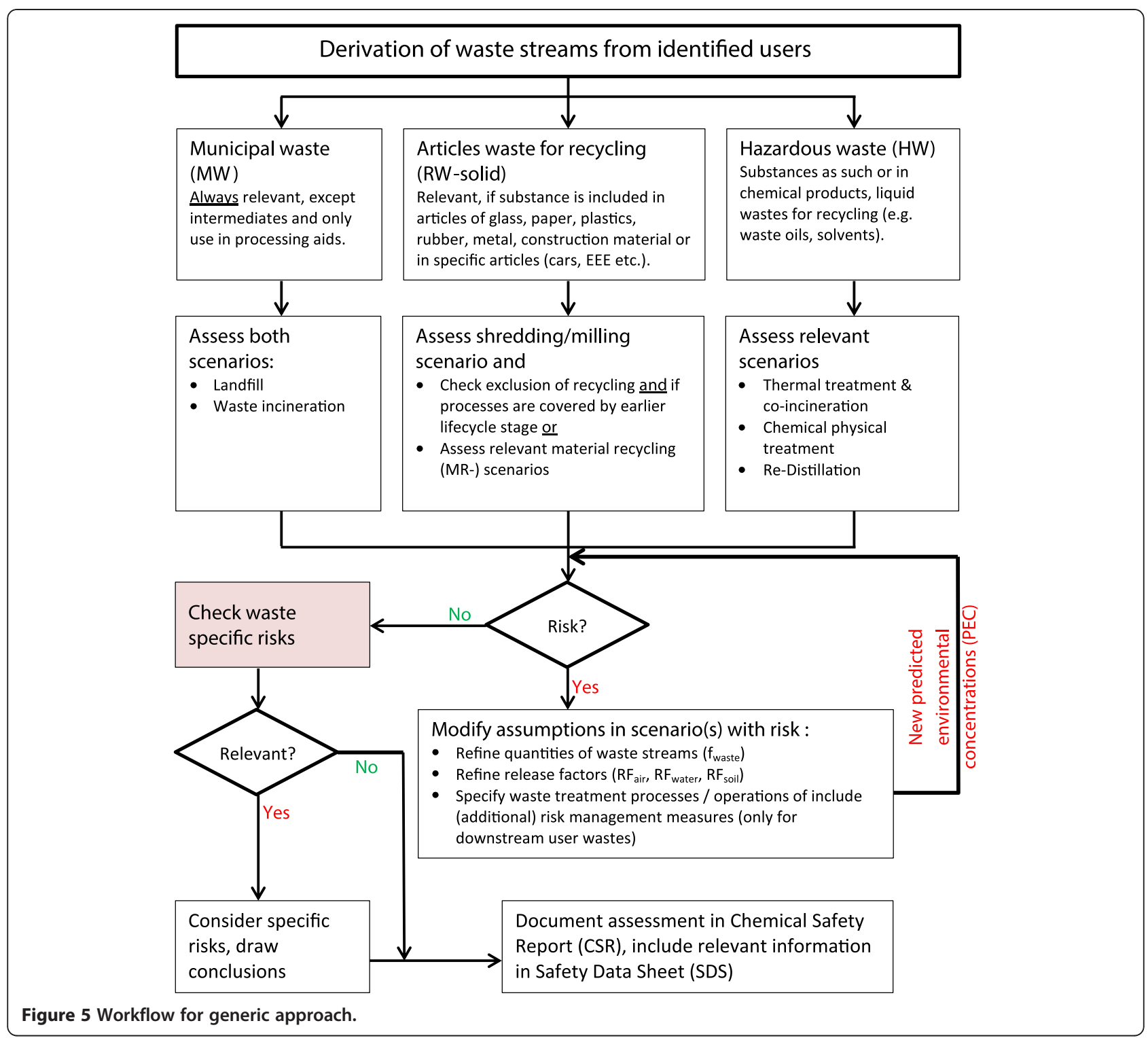

only the so-called first tranche of hazardous chemicals, and also chemicals with a market volume of over 1,000 tons per annum have been registered. Further tranches will follow the next few years.

But the analysis of the currently available registration dossiers indicates that they have some serious shortcomings. Yet unknown is whether the mandatory inclusion of the waste stage in the dossier has been realized sufficiently.

All three routes (Ecodesign, RoHS and REACH) are feasible for influencing European legislation by the outcome of the project RISKCYCLE. There is one argument that $\mathrm{REACH}$ is the most promising route: risk cycle is a "complex chemical matter". This is the original domain of REACH!

The instrumentation of $\mathrm{REACH}$ is differentiated and targeted to this complex regulatory field. And the waste phase, as shown, is explicitly subject to exposure scenario building, which in turn is the basic for substance evaluation and the resulting management measures to be derived. However, this is a good starting point for a reduction of the risk cycle problem only on paper, which is not bad, but not sufficient.

For this it must be questioned whether the stipulations in $\mathrm{REACH}$ and in the relevant guidance documents are sufficient to solve the explained problem of risk cycle. The represented stipulations for the determination of exposition scenarios in the waste stage are, in our view, sufficiently detailed as well as extensively and professionally prepared to solve the problems of risk cycle through $\mathrm{REACH}$ implementation - on paper.

The problem is the implementation of $\mathrm{REACH}$ within the personal responsibility of the registrant for his or her 
registration dossier. Our thesis is that the quality problems that are currently often deplored at the main registration pathways are likely to become even more serious on "side roads". And from the perspective of a chemical manufacturer the waste life stage is commonly seen as such a side road. To solve this, we have three suggestions:

1. The risk cycle issue should be explicitly noted in the regulatory text to raise awareness among the registrants of this topic.

2. The ongoing analysis of registration dossiers should be considered and performed with sensitivity to the waste stage. This should also be done for the selection of substances of very high concern (SVHC, candidate list). For this purpose this task should be designated to the ECHA.

3. A previous proposal given in the process of designing REACH could be helpful: the introduction of quality assurance mechanisms in REACH regulation. This proposal could not be implemented due to the lack of majority during the political decision process on structuring REACH. But today's situation shows that such a mechanism is needed. Quality assurance mechanisms could be arranged privately. Before a registration is submitted the file could be proofed by an independent expert for completeness and defined content requirements. Without such an examination a registration would be incomplete.

The auditors themselves may be obliged to undergo an approval process for independent and high quality work. Since currently on the European political agenda, the amendments to REACH are in discussion, thus 2013 would be a convenient time to introduce these three proposals.

\section{Conclusion}

There are different legal ways of addressing the problem of cycling of pollutants within global waste recycling streams. To our opinion, the most appropriate solution is to use the existing set of legal instruments of the European chemicals legislation REACH. This recommendation is based on the detailed description of the way in which waste related aspects are handled in REACH including the end of waste status in recycling processes. We propose that it should be checked whether the waste stage is described sufficiently in the available REACH registration dossiers, e.g. the recycling of electronic scrap at recycling sites with poor working conditions in Asia or Africa. Here, low standard recycling is often accompanied by pollutant emission and concentration of hazardous substances within material cycles.

This approach is confronted with some adversities. E.g. according to the position of the chemical industry only the proper and intended use of a chemical can be part of the exposure calculation within REACH. Furthermore, serious environmental problems or health impact caused by improper recycling processes occur mainly outside of Europe. To our opinion the low standard of industrial hygiene and environmental protection in emerging and developing countries is well-known and the use of improper recycling techniques is "intended". Consequentially the registrant has to include the waste phase and especially low standard recycling processes into his or her calculation of exposure.

Integrating the effects of recycling in developing countries into the REACH regulation is undoubtedly a major challenge. But without doubt avoiding the cycling of pollutants within global waste recycling streams (risk cycle) is a major challenge, too, and in addition one of the core tasks of extended producer responsibility.

\section{Methods}

Literature review, legal examination and analysis of data obtained in the RISKCYCLE project were performed to achieve the aim of the study.

\begin{abstract}
Abbreviations
CMR: Carcinogenic, Mutagenic or toxic to Reproduction; CSA: Chemical Safety Assessment; CSR: Chemical Safety Report; ECHA: European Chemicals Agency, Helsinki (Finland); LCA: Life Cycle Assessment; PBT: Persistent, Bioaccumulative and Toxic; REACH: Registration, Evaluation and Authorisation of Chemicals; RMM: Risk Management Measure; RoHS: Restriction of the use of certain Hazardous Substances in electrical and electronic equipment; SDS: Safety Data Sheet; SVHC: Substances of Very High Concern; vPvB: Very Persistent and Very Bioaccumulative; WEEE: Waste electrical and electronic equipment.
\end{abstract}

\section{Competing interests}

The authors declare that they have no competing interests.

\section{Authors' contributions}

Both authors contributed jointly and equally to the preparation of the initial manuscript. UL gave a presentation on this topic at the Riskcycle Conference on $9^{\text {th }}$ of May, 2012, in Dresden. In the following both authors actualized the script and read and approved the final manuscript.

\section{Authors' information}

Ministerial director (ret.) Professor Dr. Uwe Lahl has been Head of the Directorate General for Environmental Health, Immission Control, Safety of Installations and Transport, Chemical Safety at the Federal Ministry for the Environment, Nature Conservation and Nuclear Safety from 2001 to 2009. Within this period, of a number of German environmental regulations were made under his responsibility such as the revision of the Clean Air Act TA Luft] 2003. At the EU level, he dealt with the new European chemicals regulation $\mathrm{REACH}$.

Dr. Barbara Zeschmar-Lahl is director of the BZL GmbH, which she founded in 1994. Since 2005 she is one of the editors of the German Müll-Handbuch (handbook of waste management) www.muellhandbuchdigital.de/homepage.html.

\section{Acknowledgements}

The authors gratefully acknowledge the financial support of the Forum für Abfallwirtschaft und Altlasten e.V., Pirna (D).

\section{Author details}

${ }^{1}$ Technische Universität Darmstadt, Institut IWAR, Petersenstr. 13, Darmstadt D-64287, Germany. ${ }^{2}$ BZL Kommunikation und Projektsteuerung $\mathrm{GmbH}$, Lindenstr. 33, Oyten D-28876, Germany. 
Received: 28 August 2012 Accepted: 16 January 2013

\section{Published: 22 February 2013}

\section{References}

1. Bilitewski B, Darbra RM, Barceló D: Global risk-based management of chemical additives l: Production, Usage and Environmental Occurrence. The handbook of environmental chemistry 18. Berlin, Heidelberg: Springer; 2012. ISBN 978-3-642-24875-7 (Print) 978-3-642-24876-4 (Online).

2. Lahl U, Zeschmar-Lahl B: RISKCYCLE and EU legislation. In RISKCYCLE - risk based management of chemicals and products in a circular economy at a global scale. Dresden, 8.-9.5.2012, Conference proceedings. Beiträge zu Abfallwirtschaft/ Altlasten, Volume 87. Edited by Bilitewski B, Grundmann V, Werner P, Barcelò D, Ginebreda A, Cassal J, Darbra RM, Voet E, Rydberg T, Benfenati E. Pirna: Forum für Abfallwirtschaft und Altlasten e.V; 2012:201-212.

3. Kemna R, Elburg M, Li W, Holsteijn R: Methodology study Eco-design of energy using products. Final report. Delft: MEEUP Methodology Report; 2005. http://ec europa.eu/energy/demand/legislation/doc/2005_11_28_finalreport1_en.pdf.

4. Kemna R: Final report. Methodology for ecodesign of energy-related products. Brussels, Delft: MEErP 2011 Methodology Report. Part 1: Methods; 2011. http://www.meerp.eu/downloads/MEErP\%20Methodology\%20Part\%201\% 20Final.pdf.

5. ErP EcoReport Manual: EcoReport_2011_final.xls. www.meerp.eu/downloads/ EcoReport 2011 Final.xls.

6. Communication from the Commission to the Council and the European Parliament: Establishment of the working plan for 2009-2011 under the ecodesign directive. Brussels: COM(2008) 660 final; 2008. http://eur-lex.europa. eu/LexUriServ/LexUriServ.do?uri=COM:2008:0660:FIN:EN:PDF.

7. European Commission, Commission Staff Working Document: Establishment of the working plan 2012-2014 under the ecodesign directive. Brussels: SWD (2012) 434 final; 2012. http://ec.europa.eu/enterprise/policies/sustainablebusiness/documents/eco-design/working-plan/files/comm-swd-2012-434ecodesign_en.pdf.

8. Directive 2002/95/EC Of The European Parliament And Of The Council of: 27 January 2003 on the restriction of the use of certain hazardous substances in electrical and electronic equipment: Official Journal of the European Union L 37/19; 2003. http://eur-lex.europa.eu/LexUriServ/LexUriServ.do?uri=OJ: L:2003:037:0019:0023:en:PDF.

9. Directive 2002/96/EC Of The European Parliament And Of The Council: 27 January 2003 on waste electrical and electronic equipment (WEEE).: Official Journal of the European Union L 37/24; 2003. http://eur-lex.europa.eu/ LexUriServ/LexUriServ.do?uri=OJ:L:2003:037:0024:0038:en:PDF.

10. Directive 2011/65/EU Of The European Parliament And Of The Council: 8 June 2011 on the restriction of the use of certain hazardous substances in electrical and electronic equipment (recast): Official Journal of the European Union L 174/88; 2011. http://eur-lex.europa.eu/LexUriServ/LexUriServ.do? uri=OJ:L:2011:174:0088:0110:EN:PDF.

11. Regulation (EC) No 1907/2006 Of The European Parliament And Of The Council: 18 December 2006 concerning the registration, evaluation, authorisation and restriction of chemicals (REACH), establishing a European chemicals agency, amending directive 1999/45/EC and repealing council regulation (EEC) No 793/93 and commission regulation (EC) No 1488/94 as well as council directive 76/769/EEC and commission directives 91/155/EEC, 93/ 67/EEC, 93/105/EC and 2000/21/EC:: Official Journal of the European Union L 396/1; 2006. http://eur-lex.europa.eu/LexUriServ/LexUriServ.do?uri=OJ: L:2006:396:0001:0849:EN:PDF

12. European Chemicals Agency (ECHA): Reach. http://echa.europa.eu/web/ guest/regulations/reach.

13. European Chemicals Agency (ECHA): Most hazardous and most common chemicals registered: Press release, ECHA/PR/10/23, Helsinki; 2010. http:// echa.europa.eu/en/web/guest/view-article/-/journal_content/c63573a4-4dfe42de-bd33-0fa848c0e58e.

14. European Commission: REACH review. 2012. http://ec.europa.eu/ environment/chemicals/reach/review_2012_en.htm.

15. Lahl U, Zeschmar-Lahl B: In Going Green: Chemicals. Fields of action for a resource-efficient chemical industry. Edited by Heinrich-Böll-Stiftung. Berlin: Publication Series on Ecology; 2012:19. http://bzlinfo/de/sites/default/files/ HBS-Chemicals_web.pdf.

16. European Chemicals Agency (ECHA): Guidance on waste and recovered substances. Version; 2010. http://www.echa.europa.eu/documents/10162/ 13632/waste_recovered_en.pdf.
17. Environment Agency UK: Quality Protocol: Recycled gypsum from waste plasterboard. End of waste criteria for the production and use of recycled gypsum from waste plasterboard; 2011. http://www.environment-agency.gov.uk/static/ documents/Business/Gypsum_Quality_Protocol_NIEA_GEHO0311BTPD-E-E.pdf.

18. Council Regulation (EU): No 333/2011 of 31 march 2011 establishing criteria determining when certain types of scrap metal cease to be waste under directive 2008/98/EC of the European parliament and of the council:: Official Journal of the European Union L 92/2; 2011. http://eur-lex.europa.eu/ LexUriServ/LexUriServ.do?uri=OJ:L:2011:094:0002:0011:EN:PDF].

19. European Union: EUROPA summaries of EU legislation: Glossary; Comitology; http://europa.eu/legislation_summaries/glossary/comitology_en.htm.

20. European Commission, Joint Research Centre, Institute for Prospective Technological Studies, Sustainable Production and Consumption Unit (SUSPROC): Waste and recycling; 2011. http://susproc.jrc.ec.europa.eu/ activities/waste.

21. European Chemicals Agency (ECHA): Guidance on information requirements and chemical safety assessment. Chapter R.18: Exposure scenario building and environmental release estimation for the waste life stage. Version: 2, December 2010; http://echa.europa.eu/documents/10162/13632/r18_v2_final_en.pdf.

22. European Chemicals Agency (ECHA): Guidance on information requirements and chemical safety assessment: Chapter R.16: Environmental Exposure Estimation. Version: 2, May 2010; http://echa.europa.eu/documents/10162/ 13632/information_requirements_r16_en.pdf.

23. CEFIC Guidance: Specific environmental release categories (SPERCS). Chemical safety assessments, supply chain communication and downstream user compliance: Revision: 1, prepared by the Cefic SPERC Core Team; 2010. http://www.cefic.org/Documents/IndustrySupport/REACH\% 20Implementation/SPERC\%20Guidance.pdf.

doi:10.1186/2190-4715-25-3

Cite this article as: Lahl and Zeschmar-Lahl: Risk based management of chemicals and products in a circular economy at a global scale (risk cycle), extended producer responsibility and EU legislation.

Environmental Sciences Europe 2013 25:3.

\section{Submit your manuscript to a SpringerOpen ${ }^{\circ}$ journal and benefit from:}

- Convenient online submission

Rigorous peer review

- Immediate publication on acceptance

- Open access: articles freely available online

- High visibility within the field

- Retaining the copyright to your article

Submit your next manuscript at $>$ springeropen.com 